\title{
Non-ionic thiolated cyclodextrins - the next generation
}

This article was published in the following Dove Press journal:

International Journal of Nanomedicine

\section{Ali Moghadam ${ }^{1,2}$ \\ Muhammad ljaz ${ }^{2,3}$ \\ Mulazim Hussain Asim 2,4 \\ Arshad Mahmood ${ }^{2,5}$ \\ Max Jelkmann² \\ Barbara Matuszczak ${ }^{6}$ \\ Andreas Bernkop-Schnürch ${ }^{2}$}

'Institute of Biotechnology, College of Agriculture, Shiraz University, Shiraz, Iran; ${ }^{2}$ Center for Chemistry and Biomedicine, Department of Pharmaceutical Technology, Institute of Pharmacy, University of Innsbruck Innsbruck, Austria; ${ }^{3}$ Department of Pharmacy, COMSATS Institute of Information and Technology, Lahore, Pakistan; ${ }^{4}$ Department of Pharmaceutics, Faculty of Pharmacy, University of Sargodha, Sargodha, Pakistan; ${ }^{5}$ Department of Pharmacy, COMSATS Institute of Information Technology Abbottabad, Pakistan; ${ }^{6}$ Center for Chemistry and Biomedicine, Department of Pharmaceutical Chemistry, Institute of Pharmacy, University of Innsbruck, Innsbruck, Austria

Correspondence: Andreas BernkopSchnürch

Center for Chemistry and Biomedicine, Department of Pharmaceutical Technology, Institute of Pharmacy, University of Innsbruck, Innrain 80/82, Innsbruck 6020, Austria

$\mathrm{Tel}+435125075860 \mathrm{I}$

Fax +435I250758699

Email andreas.bernkop@uibk.ac.at
Introduction: The current study was aimed at developing a novel mucoadhesive thiolated cyclodextrin $(\mathrm{CD})$ without ionizable groups and an intact ring backbone for drug delivery.

Materials and methods: Thiolated beta $\mathrm{CD}(\beta-\mathrm{CD})$ was prepared through bromine substitution of its hydroxyl groups followed by replacement to thiol groups using thiourea. The thiolated $\beta-C D$ was characterized in vitro via dissolution studies, cytotoxicity studies, mucoadhesion studies on freshly excised porcine intestinal mucosa, and inclusion complex formation with miconazole nitrate.

Results: Thiolated $\beta$-CDs namely $\beta-\mathrm{CD}-\mathrm{SH}_{600}$ and $\beta-\mathrm{CD}-\mathrm{SH}_{1200}$ displayed $558.66 \pm 78$ and $1,163.45 \pm 96 \mu \mathrm{mol}$ thiol groups per gram of polymer, respectively. Stability constant $(\mathrm{Kc})$ of $190 \mathrm{M}^{-1}$ confirmed the inclusion complex formation of miconazole nitrate with $\beta$-CD-SH. Inclusion complexes of $\beta-\mathrm{CD}-\mathrm{SH}_{600}$ and $\beta-\mathrm{CD}-\mathrm{SH}_{1200}$ resulted in 157 - and 257 -fold increased solubility of miconazole nitrate, respectively. In addition, more than $80 \%$ of thiol groups were stable even after 6 hours at $\mathrm{pH}$ 5. Both $\beta$-CD-SH compounds showed at least 1.3 -fold improved solubility in water. In contrast to cationic thiolated CDs of the first generation, both thiomers showed no significant cytotoxicity. The mucoadhesive properties of the new thiolated CDs were 39.73- and 46.37-fold improved, respectively.

Conclusion: These results indicate that $\beta-\mathrm{CD}-\mathrm{SH}$ might provide a new favorable tool for delivery of poorly soluble drugs providing a prolonged residence time on mucosal surfaces.

Keywords: thiolated cyclodextrin, mucosal delivery, inclusion complex

\section{Introduction}

Cyclodextrins (CDs) are considered as probably the smallest polymeric backbone for thiomers representing some of the most broadly considered mucoadhesive excipients. ${ }^{1,2}$ Because of the ability of thiol groups to form disulfide bonds with mucus glycoproteins covering mucosal membranes, ${ }^{3}$ thiomers are covalently attached to the mucus layer. ${ }^{4,5}$ These unique properties guarantee the benefits of prolonged drug residence time on specific target mucosal tissues and a consequently more efficient local therapy. ${ }^{6-8}$

The first generation of thiolated CD derivatives have been developed recently. ${ }^{1,2}$ Although they were obtained under comparatively harsh conditions via oxidative opening of the glucose rings, these derivatives showed strongly improved mucoadhesive properties. Nonetheless, their ring-opened structure is certainly disadvantageous to form stable inclusion complexes especially with hydrophobic drugs and to provide subsequently sustained drug release properties. Moreover, the method of oxidative ring opening followed by the covalent attachment of thiolbearing amino ligands such as cysteamine via reductive amination results in cationic thiolated CDs. These cationic thiolated CDs, however, showed a significant toxic effect on cells. ${ }^{1,2}$ In addition, an unintended $\mathrm{pH}$-dependent drug release and even incompatibility with anionic drugs are expected consequences. ${ }^{9,10}$ 
Having on one hand the strongly prolonged mucosal residence time of thiolated CDs and taking on the other hand the drawbacks of synthesis via oxidative-ring opening and reductive amination into account, it was therefore the aim of this study to generate thiolated CDs via an alternative synthetic pathway. Beta $C D(\beta-C D)$ was chosen for this study as various derivatives of this type of $\mathrm{CD}$ have already shown great potential in drug delivery. ${ }^{8,11}$ In order to obtain non-ionic thiolated CDs without a ring opening, hydroxyl groups on the glucose subunits of $\beta-C D$ are replaced by thiol groups via bromination followed by reaction with thiourea. ${ }^{5}$ The resulting non-ionic thiolated CDs are investigated regarding cytotoxicity, mucoadhesive properties, and their ability to incorporate miconazole, serving as a hydrophobic model drug.

The novelty of this work is the synthesis of non-ionic thiolated CDs that have so far not been tested in the pharmaceutical field. The hypothesis underpinning this research is that the non-ionic thiolated CDs are less toxic and inclusion complexes of higher drug payload can be formed exhibiting a prolonged drug release compared to cationic thiolated CDs.

\section{Materials and methods}

\section{Materials}

$\beta$-CD (molecular weight: 1,134.98 Da), lithium bromide (LiBr), triphenylphosphine $\left(\mathrm{Ph}_{3} \mathrm{P}\right), \mathrm{N}, \mathrm{N}$-dimethylacetamide (DMA), N-bromosuccinimide (NBS), thiourea, 5,5'dithiobis(2-nitrobenzoic acid) (Ellman's reagent), Hanks' balanced salt solution (HBSS), resazurin (7-hydroxy3H-phenoxazin-3-one 10-oxide) sodium salt, cysteine, sodium borohydride $\left(\mathrm{NaBH}_{4}\right)$, dimethyl sulfoxide-d6 (DMSO- $\mathrm{d}_{6}$ ), tetramethylsilane (TMS), fluorescein diacetate (FDA), minimum essential medium Eagle (MEM), sodium chloride, miconazole nitrate, methanol, trifluoroacetic acid, hydrochloric acid $(\mathrm{HCl})$, acetic acid, monopotassium phosphate, dipotassium phosphate, and Triton-X 100 were all purchased from Sigma-Aldrich, Vienna, Austria.

Cell culture medium was prepared by using MEM powder 9.66 g/L (modified with Earle's salts; phenol red; 19 amino acids; and the non-essential amino acids L-asp, L-asn, L-glu, L-ser, L-ala, L-gly, and L-pro), L-glutamine $2 \mathrm{mM}$, sodium bicarbonate $2.2 \mathrm{~g} / \mathrm{L}, 1 \%$ penicillin-streptomycin solution, and $10 \%$ fetal bovine serum (FBS). FBS and $100 \mathrm{mM}$ phosphate-buffered saline (PBS) $\mathrm{pH} 6.8$ were purchased from Gibco (Invitrogen, Lofer, Austria). Pretreated standard grade regenerated dialysis tubing of cellulose membrane (molecular weight cutoff of 500-1,000 Da) was purchased from Spectrum Lab, Göttingen, Germany. All other materials were of analytical grade and received from commercial sources.

\section{Synthesis of thiolated $\beta-C D$}

$\beta-\mathrm{CD}$ as a hydrophilic polymer was chosen for the substitution of its primary and secondary hydroxyl groups with bromine moieties that were later replaced by thiol groups. Thiolated $\beta-C D$ was synthesized by replacement of hydroxyl groups with bromine that were replaced by thiol groups based on a method described previously. ${ }^{12}$ Both steps: bromination and thiolation (Figure 1) were carried out under nitrogen gas. $\beta$-CD, NBS, and $\mathrm{Ph}_{3} \mathrm{P}$ were dried in a desiccator under diminished pressure in the presence of molecular sieves $4^{\circ} \mathrm{A}$. $\mathrm{LiBr}$ anhydrous was dried at $150^{\circ} \mathrm{C}$ in an oven prior to the experiment.

First, $1 \mathrm{~g}$ of dried $\beta$-CD was dissolved in $100 \mathrm{~mL}$ of DMA, the mixture was heated for $1 \mathrm{~h}$ at $90^{\circ} \mathrm{C}$ under stirring, and then $24 \mathrm{~g}$ of $\mathrm{LiBr}$ was added slowly. This LiBr-DMA system was established to guarantee a homogeneous bromination of $\beta$-CD. ${ }^{5,13}$ The reaction mixture was kept for $1 \mathrm{~h}$ at $90^{\circ} \mathrm{C}$ until $\mathrm{LiBr}$ was completely dissolved and then maintained at $70^{\circ} \mathrm{C}$ for $14 \mathrm{~h}$ until a clear solution was obtained.

NBS and $\mathrm{Ph}_{3} \mathrm{P}$ were separately dissolved in $100 \mathrm{~mL}$ of DMA in concentrations as listed in Table 1 and gradually added to the reaction mixture, having been cooled down in ice water.

The final solution was kept at $70^{\circ} \mathrm{C}$ for $3 \mathrm{~h}$ while stirring. The brominated $\mathrm{CD}$ was precipitated by the addition of 400 $\mathrm{mL}$ of acetone (1:4). The precipitate was filtered with a Whatman filter paper, washed three times with acetone, dried in an oven at $40^{\circ} \mathrm{C}$, dissolved in water, dialyzed 2 days against water, and finally freeze-dried $\left(-51^{\circ} \mathrm{C}, 0.01 \mathrm{mbar}\right.$, Gamma LSC 1-16, Martin Christ, Osterode am Harz, Germany).

The brominated product was treated with thiourea to convert the bromide moieties to thiols. First, $1 \mathrm{~g}$ of bromo$\beta$-CD was dissolved in a solution of thiourea $(0.5 \% ; \mathrm{m} / \mathrm{v})$ in $100 \mathrm{~mL}$ of DMA and the mixture was stirred for $19 \mathrm{~h}$ at $80^{\circ} \mathrm{C}$. After cooling the reaction mixture in ice water, $20 \mathrm{~mL}$ of $3 \mathrm{M}$ $\mathrm{NaOH}$ solution was added slowly to release the free thiolated $\beta$-CD. After stirring for $15 \mathrm{~min}$ at room temperature, the mixture was neutralized with $3 \mathrm{M} \mathrm{H}_{2} \mathrm{SO}_{4}$ solution. The final product was precipitated in acetone as already described, dialyzed using cellulose membrane (molecular weight cutoff of 500-1,000 Da) against water, freeze dried, and stored at $4^{\circ} \mathrm{C}$ before use.

\section{Synthesis of a cationic thiolated $\beta-C D$}

For comparison, a cationic thiolated $\beta-\mathrm{CD}$ was synthesized in a two-step synthetic pathway by oxidizing diol groups of $\mathrm{CD}$ with $\mathrm{NaIO}_{4}$, followed by covalent coupling of cysteamine via reductive amination. ${ }^{1}$ 
A

B
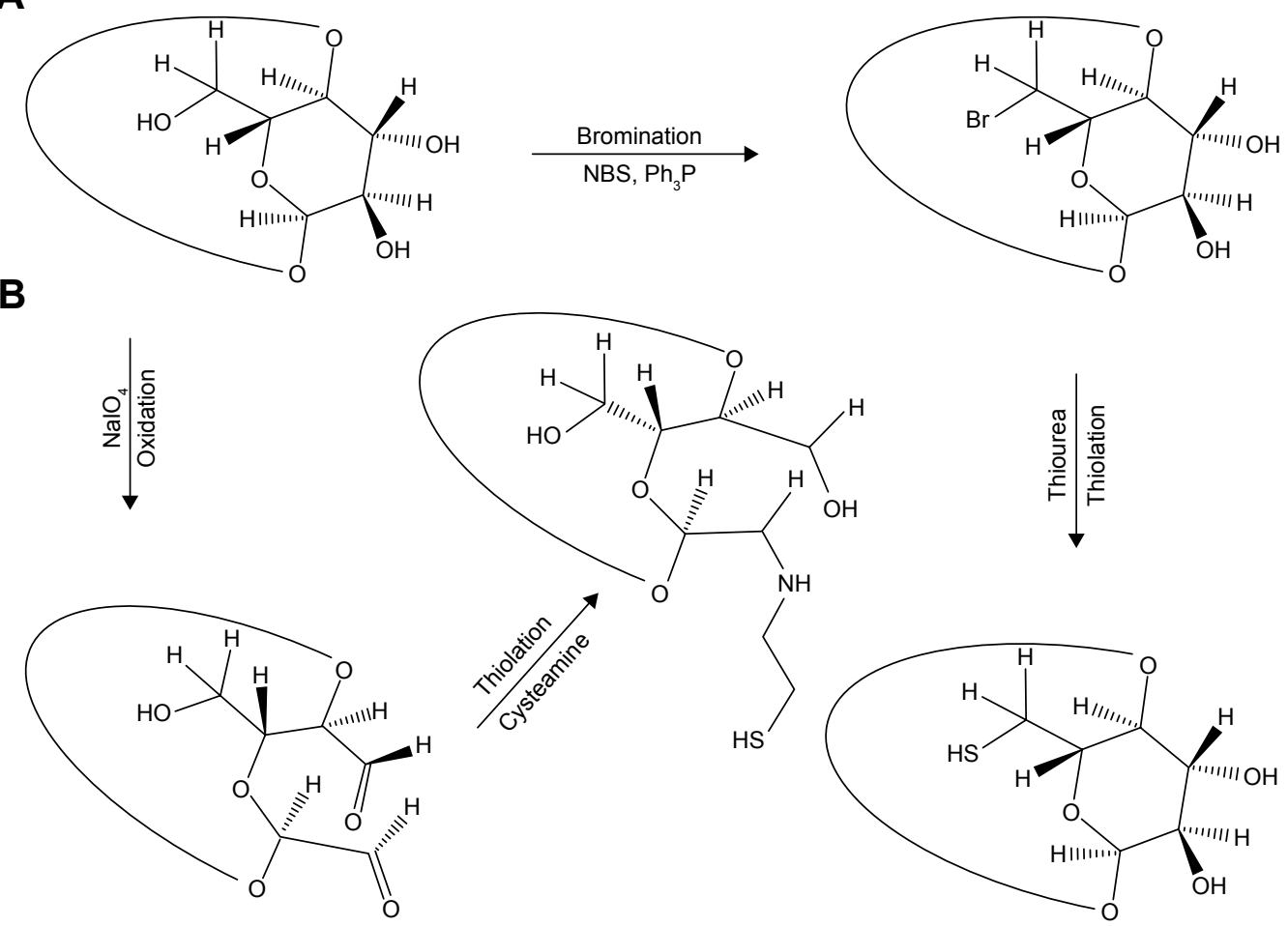

Figure I Comparison of synthetic pathways of thiolated beta-cyclodextrin ( $\beta-C D)$ derivatives. (A) Bromination of $\beta$-CD with N-bromosuccinimide (NBS) and triphenylphosphine $\left(\mathrm{Ph}_{3} \mathrm{P}\right)$ in lithium bromide ( $\left.\mathrm{LiBr}\right)-\mathrm{N}, \mathrm{N}$-dimethylacetamide $(\mathrm{DMA})$ and substitution of thiol groups using thiourea and $(\mathbf{B})$ oxidation of $\beta$-CD using sodium periodate $\left(\mathrm{NaIO}_{4}\right)$ followed by conjugation of cysteamine via reductive amination.

\section{Inclusion constant measurement}

For measurement of the stability constant phase, solubility studies were carried out according to the method of Higuchi and Connors. ${ }^{14}$ Briefly, an excess amount of miconazole nitrate was mixed in $100 \mathrm{mM}$ phosphate buffer $\mathrm{pH} 7.0$ containing increasing amounts of $\beta-\mathrm{CD}-\mathrm{SH}$, dispersed by sonicator for $30 \mathrm{~min}$, and then oscillated by a laboratory stirrer for $24 \mathrm{~h}$ at room temperature. The degree of absorption in solution was measured by ultraviolet (UV)/ visible spectrophotometer at $258 \mathrm{~nm}$ after equilibration and converted into the concentration of miconazole nitrate by using a calibration curve. The experiments were carried out in triplicate for each sample.

The phase solubility diagram was plotted by using $\beta$-CD-SH concentration as $\mathrm{X}$-coordinate and miconazole nitrate concentration as $\mathrm{y}$-axis. The stability constant, $\mathrm{Kc}$, was calculated from the straight-line portion of the phase solubility diagram according to the Higuchi-Connors equation:

$$
\mathrm{Kc}=\frac{\mathrm{A}}{[\mathrm{B}(1-\mathrm{A})]}
$$

Where A is slope and B is intercept, which could be obtained from the straight line of the phase solubility diagram.

\section{Study of thiol stability at different $\mathrm{pH}$ environments}

$\beta$-CD-SH was hydrated in demineralized water in a final concentration of $0.25 \%(\mathrm{~m} / \mathrm{v})$ and the $\mathrm{pH}$ values were stabilized with $50 \mathrm{mM}$ acetate buffer at $\mathrm{pH} 5.0,50 \mathrm{mM}$ phosphate buffer at $\mathrm{pH} 6.0$, and $50 \mathrm{mM}$ Tris buffer at $\mathrm{pH} 7.2$, respectively. The samples and controls were incubated at $37^{\circ} \mathrm{C}$ under

Table I Overview on applied reaction conditions and resulting amount of immobilized thiol (-SH) and disulfide (-S-S-) groups

\begin{tabular}{llllll}
\hline$\beta-C D(\% w / v)$ & $\mathbf{P h}_{\mathbf{3}} \mathbf{P}(\% \mathrm{~m} / \mathbf{v})$ & NBS $(\% \mathrm{~m} / \mathbf{v})$ & $\mathbf{- S H}(\mu \mathrm{mol} / \mathrm{g}$ polymer $)$ & -S-S- $(\mu \mathrm{mol} / \mathrm{g}$ polymer $)$ & *DS $(\%)$ \\
\hline$\beta-C D-S H_{1200}$ & 2 & $\mathrm{I}$ & $1,163.45 \pm 96$ & $160.13 \pm 97$ & 13.24 \\
$\beta-C D-S H_{600}$ & $\mathrm{I}$ & 0.5 & $558.66 \pm 78$ & $97.22 \pm 31$ & 6.66 \\
$\beta-C D$ control & 2 & $\mathrm{I}$ & 0 & 0 & 0 \\
\hline
\end{tabular}

Notes: Indicated values are mean \pm SD of at least three experiments; * degree of substitution; based on molecular mass.

Abbreviations: $\beta-C D$, beta-cyclodextrin; $\mathrm{Ph}_{3} \mathrm{P}$, triphenylphosphine; $\mathrm{NBS}, \mathrm{N}$-bromosuccinimide. 
permanent shaking. At predetermined time points, aliquots of $500 \mu \mathrm{L}$ were withdrawn and $50 \mu \mathrm{L}$ of $1 \mathrm{M} \mathrm{HCl}$ was added in order to quench any further reaction. ${ }^{15}$ The amount of remaining thiol groups was determined by Ellman's method as described in the following text.

\section{Determination of the thiol content}

Ellman's reagent was used to determine free thiol groups of thiolated $\beta-C D$ as described previously. ${ }^{16}$ The amount of thiol groups was assessed by using a standard curve of cysteine prepared in exactly the same way as the samples. Disulfide content was determined after reduction with $\mathrm{NaBH}_{4}$ via Ellman's test. ${ }^{13}$

\section{Characterization of thiolated $\beta-C D$ structure}

Infrared (IR) spectra were recorded on a Bruker ALPHA fourier transform (FT)-IR apparatus (Billerica, MA, USA) equipped with a platinum attenuated total reflection module. The nuclear magnetic resonance spectra were recorded in DMSO- $\mathrm{d}_{6}$ solution in $5 \mathrm{~mm}$ tubes at $30^{\circ} \mathrm{C}$ on a Varian Gemini 200 spectrometer (199.98 $\mathrm{MHz}$ for ${ }^{1} \mathrm{H}, 50.29 \mathrm{MHz}$ for ${ }^{13} \mathrm{C}$ ). The center of the solvent multiplet (DMSO- $\mathrm{d}_{6}$ ) was used as internal standard (chemical shifts in $\delta$ ppm), which was related to TMS with $\delta 2.49 \mathrm{ppm}\left({ }^{1} \mathrm{H}\right)$ and $39.5 \mathrm{ppm}\left({ }^{13} \mathrm{C}\right)$.

\section{Water solubility}

Solubility of unmodified and modified $\beta-C D$ was determined using turbidity measurement method. ${ }^{17}$ In brief, gradually increasing amounts of test compounds from 5, 10 to $30 \mathrm{mg}$ were dissolved in $1 \mathrm{~mL}$ of distilled water and vortexed for $5 \mathrm{~min}$ at room temperature. Subsequently turbidity was measured using a UV-visible spectrophotometer (UV-1240; Shimadzu, Kyoto, Japan) at a wavelength of $595 \mathrm{~nm}$.

\section{Moisture content}

All the complexes were weighed $\left(W_{1}\right)$ and kept in a desiccator containing anhydrous calcium chloride at $37^{\circ} \mathrm{C}$ for $24 \mathrm{~h}$. After that, complexes were removed from the desiccators and reweighed until a constant weight $\left(W_{2}\right)$ was obtained. The percentage moisture loss was calculated using the following equation: ${ }^{18}$

$$
\text { Moisture loss }(\%)=\frac{W_{1}-W_{2}}{W_{1}} \times 100
$$

$W_{1}$ is the initial weight of the complex and $W_{2}$ is the final weight of the complex.

\section{Liquid chromatography - mass spectrometry}

Mass spectrometry detection was carried out using micrOTOF-Q II (Bruker) controlled by a computer running the "HyStar 3.2" acquisition software.

Source conditions were as follows: capillary voltage: $4.5 \mathrm{kV}$; end plate offset: $-500 \mathrm{~V}$; quadrupole ion energy: $5 \mathrm{eV}$; nebulizer: 4.4 psi; cone gas flow (nitrogen) gas: $6 \mathrm{~L} / \mathrm{min}$; dry temperature: $200^{\circ} \mathrm{C}$. Sample solutions were prepared by dissolving the complex mixtures in the mobile phase (methanol, $0.1 \%$ formic acid; $85: 15 \%$ ) to reach the concentration of $500 \mathrm{ng} / \mathrm{mL}$.

Mass spectral studies were performed in positive electrospray ionization (ESI) mode in the mass range of $\mathrm{m} / \mathrm{z}$ $417 \rightarrow 415$ to quantify the drug. In order to get a clear mass spectrum without any background noise, the drug was directly infused using a syringe pump into the mass spectrometer.

The stock solution of miconazole was prepared in a concentration of $1.0 \mathrm{mg} / \mathrm{mL}$ (methanol $/ 0.1 \%$ formic acid $85: 15 \% \mathrm{v} / \mathrm{v}$ mixture) for mass spectrometric analysis performed via direct infusion of the samples. Calibration standards were prepared by diluting the stock solution to the concentrations of 7.81 , $15.62,31.25,62.5,125,250$, and $500 \mathrm{ng} / \mathrm{mL}$. The complex concentrations were prepared in the same way as calibration samples to the concentrations of 125,250 , and $500 \mathrm{ng} / \mathrm{mL}$.

\section{Cytotoxicity studies Resazurin assay}

Caco-2 cells were purchased from the European Collection of Authenticated Cell Cultures (Wiltshire, UK). Cells (passage number 25-33) were seeded at a density of $2.5 \times 10^{4}$ cells/well in a 24 -well plate in a final volume of $500 \mu \mathrm{L}$ of MEM with Earle's balanced salts supplemented with $10 \%$ FBS, $1 \%$ penicillin-streptomycin, and $2.0 \mathrm{mM}$ L-glutamine at $37^{\circ} \mathrm{C}$ in a $5 \% \mathrm{CO}_{2}$ environment. The medium was refreshed every other day.

Resazurin assay is performed as an oxidation-reduction indicator in cell viability assays. Resazurin (7-hydroxy-3Hphenoxazin-3-one 10-oxide) is a blue dye, itself weakly fluorescent until it is irreversibly reduced to the pink colored and highly red fluorescent resorufin by alive cells. When the cells were $\sim 80 \%$ confluent ( $80 \%$ of surface of flask covered by cell monolayer after $8-10$ days), they were washed twice with PBS pre-warmed at $37^{\circ} \mathrm{C}$. Test solutions including unmodified $\beta-\mathrm{CD}, \beta-\mathrm{CD}-\mathrm{SH}_{600}, \beta-\mathrm{CD}-\mathrm{SH}_{1200}$ (Table 1), the cationic reference $\beta$-CD-SH $(0.5 \%$ and $1 \% ; \mathrm{m} / \mathrm{v})$ positive control prepared in white MEM, and negative control $(1 \% \mathrm{v} / \mathrm{v}$ Triton X-100) were added in $500 \mu \mathrm{L}$ volume in triplicate to 
the cell culture. Then, the treated cells were incubated at $37^{\circ} \mathrm{C}$ in a $5 \% \mathrm{CO}_{2}$ environment for 24 and $72 \mathrm{~h}$. Then, test solutions were removed, and cells were washed twice with pre-warmed PBS. A diluted resazurin solution $(2.2 \mu \mathrm{M})$ in $500 \mu \mathrm{L}$ volume was added to each well and cells were incubated for $3 \mathrm{~h}$. Supernatant $(100 \mu \mathrm{L})$ was afterwards transferred to a black 96-well plate and fluorescence intensity was measured using microplate reader (M200 spectrometer; Tecan Infinite, Grödig, Austria) at a wavelength of $540 \mathrm{~nm}$ with background subtraction at $590 \mathrm{~nm}$. Percentage of viable cells was calculated according to the following equation:

Cell viability (\%)

$$
=\frac{\text { Experimental values }- \text { negative }}{\text { Positive control }- \text { negative }} \times 100
$$

\section{LDH assay}

In parallel to the resazurin assay, lactate dehydrogenase (LDH) release assay was performed. In brief, if test samples damaged cell membrane integrity, cytoplasmic $\mathrm{LDH}$ is released into culture medium. ${ }^{6}$ The amount of LDH leakage is then measured using a commercial test kit (Promega, Madison, WI, USA). In detail, the cells with $\sim 80 \%$ confluence were washed with pre-warmed HBSS before being treated with unmodified or modified samples $(0.5 \%$ and $1 \% ; \mathrm{m} / \mathrm{v})$ as already described. HBSS was used as negative control and Triton-X $100(1 \% ; \mathrm{m} / \mathrm{v})$ served as positive control. After 24 and $72 \mathrm{~h}$ of incubation at $37^{\circ} \mathrm{C}$ in $5 \% \mathrm{CO}_{2}$ environment, supernatant was collected and LDH assay was performed according to the manufacturer's instruction. Fluorescence was recorded using a microplate reader (M200 spectrometer; Tecan Infinite) with an excitation wavelength of $560 \mathrm{~nm}$ and an emission wavelength of $590 \mathrm{~nm}$. The percentage of cell toxicity was estimated according to the following equation:

\section{Cytotoxicity (\%)}

$$
=\frac{\begin{array}{c}
\text { Average fluorescence } \\
\text { intensity of each sample }
\end{array}}{\text { Average fluorescence }} \times 100
$$

\section{In vitro evaluation of mucoadhesive properties}

For the evaluation of mucoadhesive properties, $\beta$-CDs were fluorescently labeled by incorporation of FDA. Briefly, $20 \mathrm{mg}$ of $\mathrm{CD}$ was dissolved in $20 \mathrm{~mL}$ of demineralized water. $\mathrm{pH}$ was adjusted to 6.5 with $100 \mathrm{mM} \mathrm{HCl}$. In all, $1 \mathrm{mg}$ of FDA was dissolved in $5 \mathrm{~mL}$ of $96 \%$ ethanol and $1 \mathrm{~mL}$ of this solution was added to each CD solution. After $24 \mathrm{~h}$ of stirring at room temperature, the suspensions were filtered in order to eliminate unentrapped FDA and freeze dried.

Freshly excised porcine intestinal mucosa collected from a local slaughterhouse was used for the mucoadhesion test. First, the porcine small intestine was rinsed with $100 \mathrm{mM}$ PBS pH 6.8. Then, it was cut into smaller pieces of $4 \times 2 \mathrm{~cm}$ and fixed on half-cut $50 \mathrm{~mL}$ falcon tubes that were placed at an angle of $45^{\circ}$ in an incubation chamber of $37^{\circ} \mathrm{C}$ and $100 \%$ relative humidity. Subsequently, the mucosa was continuously rinsed with the same phosphate buffer for $5 \mathrm{~min}$ at a flow rate of $1 \mathrm{~mL} / \mathrm{min}$. Then, $20 \mathrm{mg}$ of FDA-labeled $\beta-C D$ samples were separately placed on the mucosa and after $10 \mathrm{~min}$, the phosphate buffer flow was restarted. Then, $30 \mathrm{~mL}$ of phosphate buffer flowing down the mucosa was collected at the following time points: 30,60, 90, 120, and $180 \mathrm{~min}$. In parallel, standard (100\%) samples were prepared by allowing $30 \mathrm{~mL}$ of phosphate buffer to flow on the mucosa and then dissolving $20 \mathrm{mg}$ of CDs in the collected buffer.

To quantitatively hydrolyze FDA to sodium fluorescein, $25 \mathrm{~mL}$ of $\mathrm{NaOH} 5 \mathrm{M}$ was added to $30 \mathrm{~mL}$ of the collected samples and the remaining intestine on the falcon tube. Samples were incubated while shaking at $37^{\circ} \mathrm{C}$ for $20 \mathrm{~min}$ and then centrifuged at 13,400 rpm at room temperature for $5 \mathrm{~min}$. Finally, $100 \mu \mathrm{L}$ of each sample was transferred to the microplate reader (M200 spectrometer; Tecan Infinite) and fluorescence intensity was measured at an emission wavelength of $535 \mathrm{~nm}$ and an excitation wavelength of $485 \mathrm{~nm}$.

\section{HPLC analysis}

Drug loading was measured by high-performance liquid chromatography (HPLC) using ProntoSIL C18 column (250 4.6 mm, $5 \mu \mathrm{m}$; Bischoff Chromatography, Leonberg, Germany) and a mobile phase containing $0.1 \%$ trifluoroacetic acid and methanol in a ratio of 15:85. Detection was performed in UV at $\lambda=235 \mathrm{~nm}$, where the miconazole nitrate reached the maximum level of absorption, while retention time was at $7.6 \mathrm{~min}$.

Measurement was conducted by integration of peak areas, and loaded drug was quantified by using a standard curve (coefficient $r^{2}=0.9997$ ) that was prepared by dissolving miconazole nitrate in methanol.

\section{Inclusion complexes and drug loading}

Inclusion complexes of miconazole nitrate with unmodified and thiolated $\beta$-CDs were prepared according to a method described by Wang and Cai. ${ }^{15}$ In brief, $25 \mathrm{mg}$ of miconazole nitrate dissolved in $5 \mathrm{~mL}$ of ethanol was added to $30 \mathrm{~mL}$ of 
$50 \mathrm{mM}$ phosphate buffer $\mathrm{pH} 6.8$ containing $75 \mathrm{mg}$ of CDs (molar ratio; 1:1), separately. Reaction mixtures were stirred at room temperature for $24 \mathrm{~h}$. Then, the mixtures were filtered using a $0.2 \mu \mathrm{m}$ size membrane filter and freeze dried.

\section{Dissolution study}

To calculate the influence of the inclusion complex of unmodified $\beta-C D$ and thiolated $\beta-C D$ on dissolution of miconazole nitrate, $30 \mathrm{mg}$ of each inclusion complex of pure miconazole nitrate was compressed into tablets (single puncher machine, D-7064; Paul Weber, Remshalden-Grunbach, Germany). The compressed tablets were placed in Erlenmeyer flasks containing $6 \mathrm{~mL}$ of $100 \mathrm{mM}$ phosphate buffer $\mathrm{pH} 6.8$. The flasks were placed on a rocker in an incubator at $37^{\circ} \mathrm{C}$ with $100 \%$ relative humidity. Aliquots of $200 \mu \mathrm{L}$ were taken at predetermined time points and replaced by an equal volume of fresh medium. All samples were centrifuged and filtrated. The concentration of dissolved drug in these samples was determined via HPLC as already described.

\section{Statistical analysis}

The statistical difference among groups was compared by one-way analysis of variance (ANOVA) and $p<0.05$ or $p<0.01$ was considered statistically significant (GraphPad Prism 5.01; GraphPad Software, Inc., CA, USA). In addition, Student's $t$-test was applied with a confidence interval $(p<0.05)$ for the analysis of two groups.

\section{Results and discussion Synthesis of thiolated $\beta-C D$}

In order to synthesize thiolated $\beta-C D$, the hydroxyl groups on the carbohydrate backbone were replaced by thiol moieties as shown in Figure 1A. In contrast to the synthetic pathway having been used as illustrated in Figure 1B, there was no ring opening necessary. The intermediate products were odorless, composed of fine structures, and light yellow most likely due to bromine ion on the carbohydrate ring. As the primary hydroxyl groups display the highest reactivity to nucleophilic substitution compared to secondary hydroxyl groups, hydroxyl groups at the terminal site of polysaccharide chains are likely favored for this type of substitution. ${ }^{19,20}$ The final thiolated $\beta-C D$ product appeared as a fibrous structured polymer, odorless, white, and being soluble at physiological $\mathrm{pH}$ in aqueous media. The yield in hydroxyl groups having been substituted by thiol groups in dependence on the applied concentration of NBS and $\mathrm{Ph}_{3} \mathrm{P}$ is illustrated in Table 1.

Comparing the content of immobilized thiol groups on $\beta$-CD-SH revealed almost two times higher degree of substitution (DS) when a twice as high concentration of $\mathrm{Ph}_{3} \mathrm{P}$ and NBS was applied in the first step of the reaction. This effect might be explained by the higher bromination substitutions on the backbone unit of the polymer, due to these reaction improvements, as shown in Table 1. Moreover, as increasing concentrations of thiourea had no effect on the thiolation efficiency, it can be assumed that the efficiency of the thiolation reaction is strongly dependent on the degree of bromination. ${ }^{5}$ An efficient regioselective bromination of cellulose was achieved using $\mathrm{NBS} / \mathrm{Ph}_{3} \mathrm{P}$ in $\mathrm{DMA} / \mathrm{LiBr}$, giving a 6-bromo-6deoxycellulose with $\mathrm{DS}=0.9 .{ }^{21}$ Similarly, thiolation reactions of other polysaccharides in this homogeneous system led to high regioselectivity and high degrees of substitutions. ${ }^{5,20}$ To a minor extent, these thiol groups were oxidized to disulfide substructures. Generally, in the case of $\beta-\mathrm{CD}-\mathrm{SH}_{1200}$, on average each $\mathrm{CD}$ molecule exhibited one free thiol group.

The successful immobilization of thiol groups was further confirmed by the results obtained from FT-IR spectroscopy. The FT-IR spectra of $\beta$-CD-SH and $\beta$-CD are shown in Figure S1. The infrared spectra of the thiolated derivatives differ significantly from that of the unmodified $\mathrm{CD}$. In detail, in the case of $\beta-\mathrm{CD}-\mathrm{SH}_{600}$ and $\beta-\mathrm{CD}-\mathrm{SH}_{1200}$, there are strong bonds at 1,137 or $1,136 \mathrm{~cm}^{-1}$ as well as moderate bonds at $624 \mathrm{~cm}^{-1}$ that should be interpreted as CS stretching vibrations. ${ }^{6}$

Chemical structure of $\beta$-CD-SH was confirmed via ${ }^{13} \mathrm{C}$ NMR spectral analysis. Comparison of the ${ }^{13} \mathrm{C}$ NMR spectrum of $\beta$-CD-SH with that of unmodified $\beta$-CD showed numerous additional signals of aliphatic carbon atoms present in $\beta$-CD-SH indicating the introduction of the sulfhydryl ligand. Comparison of the ${ }^{1} \mathrm{H}$ NMR spectra of unmodified $\beta-\mathrm{CD}$ with those of the modified derivatives indicates that in the case of $\beta-\mathrm{CD}-\mathrm{SH}_{600}$ and $\beta-\mathrm{CD}-\mathrm{SH}_{1200}$ there are additional signals at 7.4, 7.1, and $6.9 \mathrm{ppm}$ that are exchangeable with $\mathrm{D}_{2} \mathrm{O}$ and may be assigned to the protons of the thiol groups (Figure S2A-D).

The ${ }^{13} \mathrm{C}$ NMR spectra of thiolated CDs are characterized by additional signals in the aliphatic range (at 26.0, 21.9 , and 20.5 for $\beta-\mathrm{CD}-\mathrm{SH}_{600}$, and at 26.0 and $20.5 \mathrm{ppm}$ for $\beta-\mathrm{CD}-\mathrm{SH}_{1200}$ ) representing thiol-bearing carbon atoms (Figure S3A-D).

\section{Phase solubility and the inclusion constant}

Phase solubility studies were carried out at room temperature in buffer at $\mathrm{pH} 7$ to calculate the solubility constant Kc. The phase solubility diagram of miconazole nitrate with $\beta-\mathrm{CD}-\mathrm{SH}$ is illustrated in Figure 2 showing a linear trend. According 


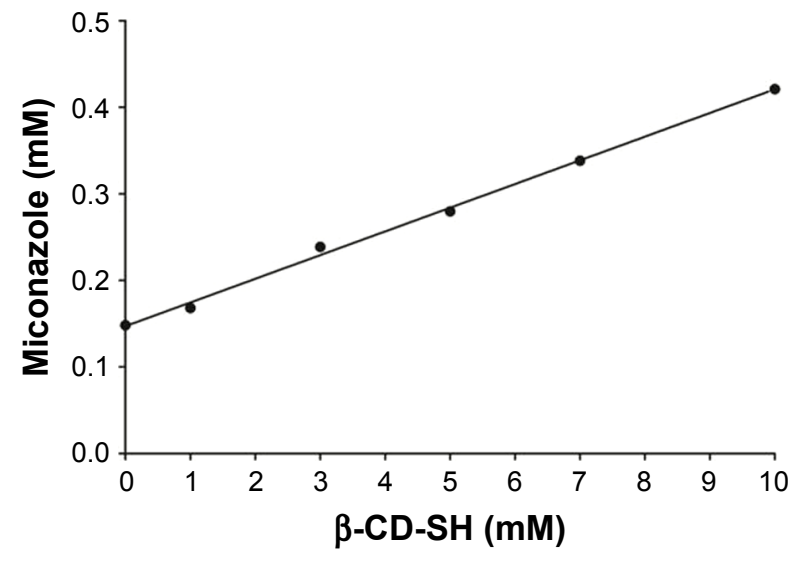

Figure 2 Phase solubility study of miconazole nitrate with beta-cyclodextrin $(\beta-C D)-S H$ in $100 \mathrm{mM}$ phosphate buffer $\mathrm{pH}$ 7.0.

to these results, the formation of 1:1 inclusion complexes seems likely. The stability constant $\mathrm{Kc}$ of the complexes of miconazole nitrate with $\beta$-CD-SH at $\mathrm{pH} 7$ was calculated using Equation 1 and is summarized in Table 2.

\section{Study of thiol stability in different $\mathrm{pH}$ environments}

Depending on the $\mathrm{pH}$ value of the thiomer solution, the thiol groups of the polymer conjugates were oxidized, thereby forming intermolecular as well as intramolecular disulfide bonds. These results are illustrated in Figure 3. At pH 5, the thiol groups of the $\beta$-CD-SH remained more stable towards oxidation, whereas a significant decrease in the thiol group content could be observed at $\mathrm{pH} 6$ and 7.2. After 6 hours at $\mathrm{pH} 5$, more than $80 \%$ thiols were stable. This observation can be explained by the decreasing $\mathrm{H}^{+}$concentration on raising $\mathrm{pH}$ values resulting in turn in a higher amount of negative thiolate anions, $\mathrm{S}^{-}$, representing the active form for oxidation.

\section{Solubility}

H-bond supported that self-aggregation of hydrated $\beta-C D$ causes limited aqueous solubility and leads to physical instability of aqueous $\beta$-CD solutions. ${ }^{22}$ This comparatively poor aqueous solubility of $\beta-C D$ is certainly limiting its potential use for various pharmaceutical applications. The solubility of $\beta$-CD, however, was improved from $1.85 \mathrm{~g} / 100 \mathrm{~mL}$ to

Table 2 The inclusion constant of miconazole nitrate with $\beta-C D-S H$

\begin{tabular}{llll}
\hline $\mathbf{p H}$ & Linear equation & $\boldsymbol{r}^{2}$ & $\mathbf{K c}\left(\mathbf{M}^{-1}\right)$ \\
\hline 7 & $\mathrm{y}=0.0274 \mathrm{x}+0.147 \mathrm{I}$ & 0.9972 & 190 \\
\hline
\end{tabular}

Abbreviation: $\beta-C D$, beta-cyclodextrin.

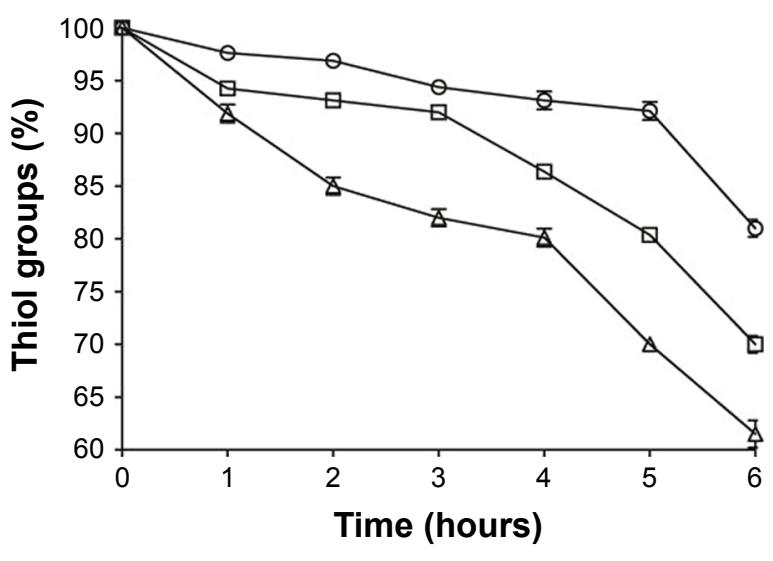

Figure 3 Stability of thiol groups at different $\mathrm{pH}$ environments at $37^{\circ} \mathrm{C}$. Notes: $(\bigcirc) \mathrm{pH} 5,(\square) \mathrm{pH}$ 6, and $(\Delta) \mathrm{pH}$ 7.2. Indicated values are mean \pm SD.

$2.89 \mathrm{~g} / 100 \mathrm{~mL}$ in the case of $\beta-\mathrm{CD}-\mathrm{SH}_{1200}$, corresponding to a 1.36-fold improvement. (Figure 4; Table S1).

This unexpected result can be explained by the disruption of the stable, restrictive hydrogen bond system around the $\mathrm{CD}$ ring through insertion of disturbing thiol groups. Szente and Szejtli, for instance, could also show improved solubility of CD by introducing some methylated moieties to the ring system. ${ }^{23}$

\section{Cytotoxicity}

The potential use of CDs and their synthetic derivatives has been widely regarded as improving certain properties of the drugs, such as stability, solubility, and bioavailability. ${ }^{24}$ Safety is a primary concern when considering new excipients intended for use in pharmaceutical formulations, and so the toxicological matters together with the biological fate of CDs must be comprehensively investigated before practical use can be considered. ${ }^{24}$ The cytotoxic effect of both $\beta-C D$

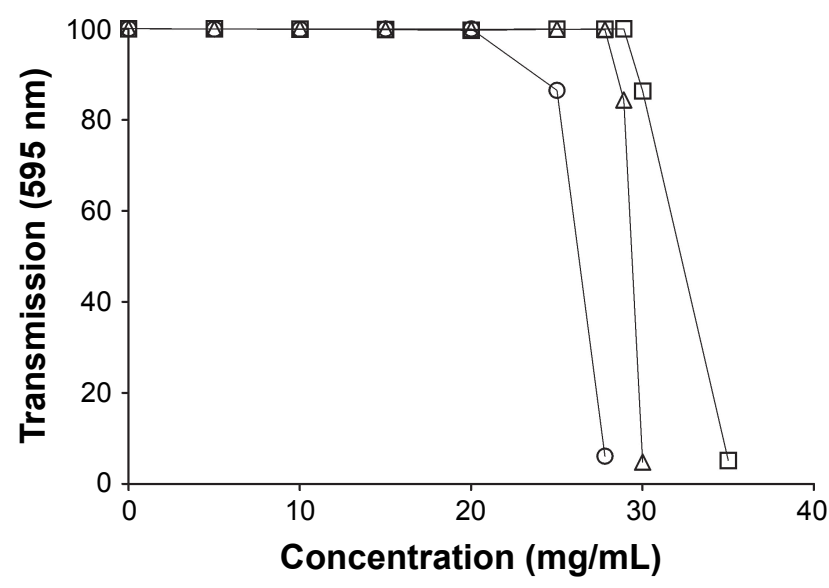

Figure 4 Water solubility determined with the turbidity method at $595 \mathrm{~nm}$. Notes: $(\bigcirc) \beta-C D,(\square) \beta-C D-S H_{600},(\Delta) \beta-C D-S H_{1200}$. Indicated values are mean \pm $\mathrm{SD}$ of three experiments. 
and $\beta$-CD-SH on Caco- 2 cells was assessed by two methods, resazurin and $\mathrm{LDH}$ assays. Cells were treated with $\beta-\mathrm{CD}-$ $\mathrm{SH}_{600}, \beta-\mathrm{CD}-\mathrm{SH}_{1200}$, and the cationic $\beta-\mathrm{CD}-\mathrm{SH}$ of the first generation in two concentrations. Results confirmed that the new thiolated CDs do not show significant toxicity ( $p<$ $0.05)$, as cell viability was more than $92 \%$ even after treatment with the higher concentration of $1 \%$ (Figure $5 \mathrm{~A}$ ).

In addition, no significant difference could be detected between incubation periods of 24 and $72 \mathrm{~h}$ for both concentrations and even with increasing degree of thiolation as shown in Figure 5A. By contrast, the cationic $\beta-\mathrm{CD}-\mathrm{SH}$ showed a pronounced toxic effect increasing over time (Figure 5A). Results of LDH assay are shown in Figure 3. Cationic $\beta$-CD-SH exposure led to cell toxicity, whereas exposure with $0.5 \%$ and $1 \% \beta-\mathrm{CD}-\mathrm{SH}$ of the second generation showed no significant difference in comparison to the negative control, within $24 \mathrm{~h}$ (Figure 5B). These results are in good accordance with the resazurin results (Figure 5B).

It has been previously confirmed that thiol groups are key regulators of intracellular adhesion molecule-1 (ICAM-1) expression in the process of cell attachment. ${ }^{25,26}$ For example, L-cysteine blocks the ketone-induced and high-glucose adhesion of monocytes to endothelial cells because of depressing ICAM-1 expression through inhibition of the reactive oxygen species pathway. On the other hand, Mukherjee et al verified that extremely excessive $\mathrm{N}$-acetylcysteine generates a tense condition in endothelial cells. This phenomenon results in induced expression of ICAM-1, which becomes the target

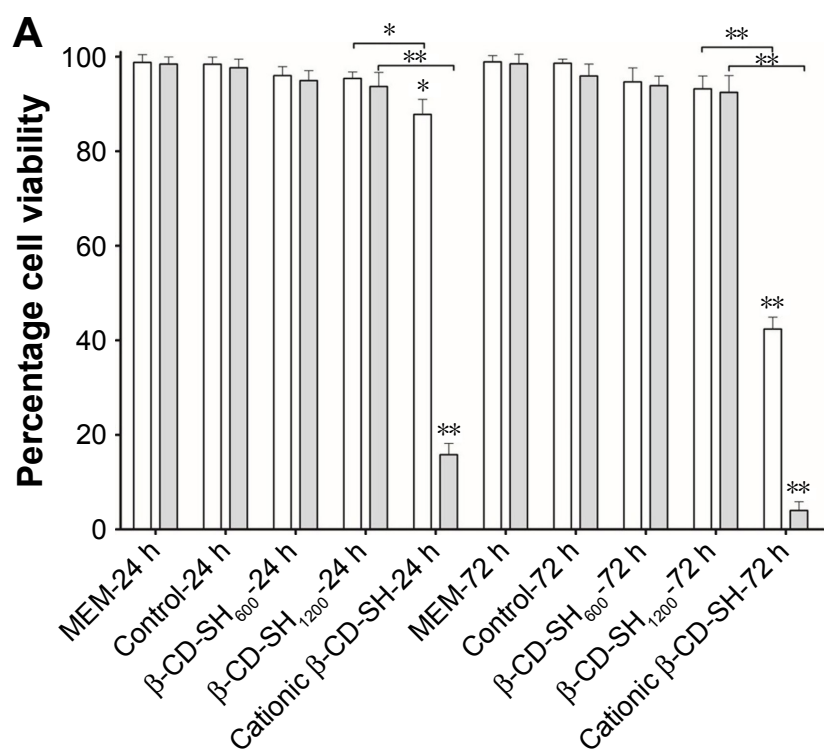

of endosomal and proteolytic degradation, thus increasing functional ICAM-1 on the cell surface. ${ }^{25}$ According to these considerations, thiol groups of $\beta$-CDs will likely interact with cells. Results, however, showed that these presumptive interactions have no significant impact on cell viability. By contrast, the charge of $\beta$-CDs seems to have a pronounced effect. The comparatively high toxicity of cationic $\beta-\mathrm{CD}-\mathrm{SH}$ can be explained by its positive charge at physiological $\mathrm{pH}$ due to the secondary amino groups likely ionically interacting with the anionic cell surfaces substructures, such as heparin sulfate proteoglycans, and subsequently destabilizing cell membrane integrity. ${ }^{25}$ Apart from that, it is well known that $\beta$-CDs interact with cell membrane cholesterol causing cytotoxicity. Kiss et al, for instance, confirmed that even cholesterol-solubilizing properties can be a predictive factor for $\beta$-CD cell toxicity, which depends on the structure of the $\mathrm{CD}$ derivative, eg, on the number and position of the new groups and the presence of ionic groups. ${ }^{33}$ Due to the addition of cholesterol to final formulations, however, this toxic effect might be compensated. ${ }^{11}$

\section{Mucoadhesive properties}

The enhancement of drug activity and selective transfer or the reduction of side effects can be achieved by inclusion complex formation. ${ }^{27}$ The CD complexation enables the development of formulations for drugs that are difficult to formulate and deliver with the existing pharmaceutical excipients, which is reflected in the increasing number of pharmaceutical products

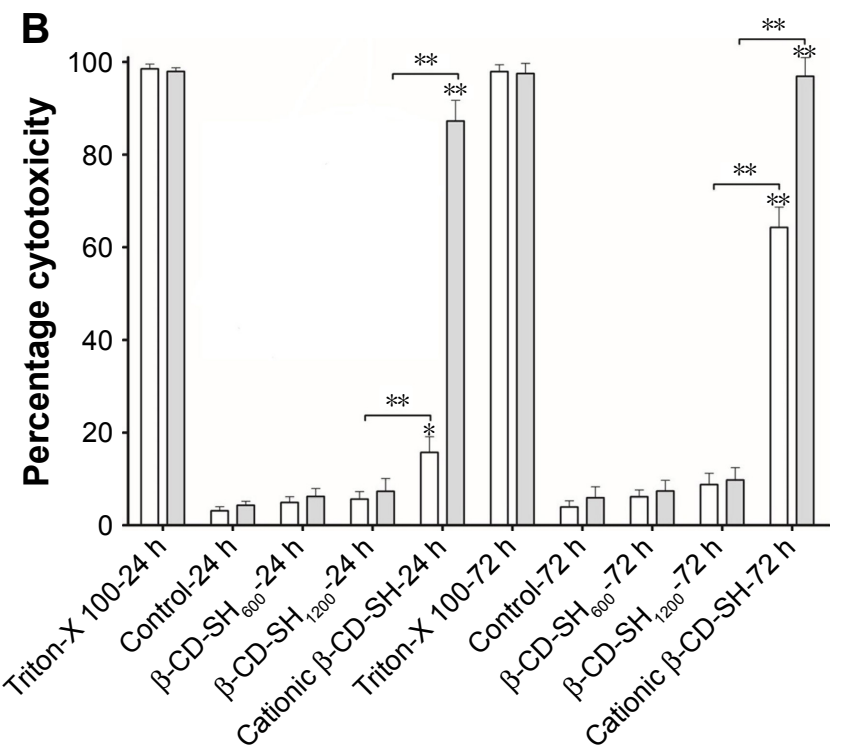

Figure 5 Cytotoxic effect of thiolated beta-cyclodextrin $(\beta-C D)$ on Caco-2 cells as demonstrated by $(\mathbf{A})$ resazurin and $(\mathbf{B})$ lactate dehydrogenase $(\mathrm{LDH})$ assays. Notes: Caco-2 cells were treated with $0.5 \%$ (white bar) and I\% (gray bar) of indicated compounds for 24 and 72 h. All values are the means of triplicate experiments \pm SD; $*_{p}>0.05, * * p>0.01$.

Abbreviations: $\beta-C D$, beta-cyclodextrin; MEM, minimum essential medium Eagle. 
being available in the market as CD-based formulations. ${ }^{24}$ However, actual and potential use of $\mathrm{CD}$ derivatives with more favorable safety profiles has renewed interest in extended use of CDs for drug delivery via various routes. ${ }^{24}$ Mucosal administration is thereby among the most attractive ones.

The mucoadhesive properties of polymers are dependent on interactions between functional moieties of the mucus gel layer and the mucoadhesive polymers. ${ }^{28}$ In the case of CDs, the most likely important interactions being responsible for mucoadhesive properties - namely ionic interactions and chain entanglements - cannot take place without sacrificing their non-ionic character, thus explaining their comparatively poor mucoadhesive properties. The mucoadhesive properties of CDs and hydroxypropyl- $\beta-C D$ have been reported previously by Gavini et al and Francois et al. ${ }^{29,30}$ The mucoadhesive properties of CDs can likely be strongly improved via thiolation allowing $\mathrm{CDs}$ to form disulfide bonds with cysteine-rich subdomains of mucus glycoproteins.

Mucoadhesion study of thiolated $\beta-\mathrm{CD}$ on porcine intestinal mucosa confirmed that this type of thiomers show strongly improved mucoadhesive properties. In detail, $\beta-\mathrm{CD}-\mathrm{SH}_{600}$ and $\beta$-CD-SH ${ }_{1200}$ exhibited 39.73- and 46.37-fold higher mucoadhesion in comparison to unmodified $\beta$-CDs, respectively (Table 3). As shown in Figure 6, thiolated $\beta$-CDs were able to adhere and remain for a longer period on the intestinal mucosa and more than $52 \%$ of $\beta-\mathrm{CD}-\mathrm{SH}_{1200}$ remained on the intestinal mucosa after $3 \mathrm{~h}$. Application of just the fluorescence marker FDA to the mucosa showed that it is - although insoluble in aqueous media - washed off the mucosa in a considerably short time period in a similar manner as the unmodified $\beta-C D$. These data demonstrated that applying poorly soluble drugs in suspension to mucosal membranes could not provide a prolonged residence time there.

\section{Inclusion complex forming properties}

The maximum amount of miconazole nitrate that could be incorporated in unmodified and modified CDs is shown in Table S2. Inclusion complexes prepared with $\beta-\mathrm{CD}-\mathrm{SH}_{600}$ and

Table 3 Comparison of percentage of thiolated CDs remaining attached to porcine intestinal mucosa for a period of $3 \mathrm{~h}$ and the resulting improvement ratio with respect to unmodified $\beta-C D$

\begin{tabular}{lll}
\hline Polymer & \% remaining after $\mathbf{3} \mathbf{~}$ & Improvement ratio \\
\hline$\beta-\mathrm{CD}$ & $\mathrm{I} .13 \pm 0.24$ & $\mathrm{I}$ \\
$\beta-\mathrm{CD}-\mathrm{SH} \mathrm{H}_{600}$ & $44.9 \pm 1.43$ & 39.73 \\
$\beta-\mathrm{CD}-\mathrm{SH}_{1200}$ & $52.4 \pm 1.87$ & 46.37 \\
\hline
\end{tabular}

Note: All values are the mean \pm SD of triplicate experiments.

Abbreviation: $\beta-C D$, beta-cyclodextrin.

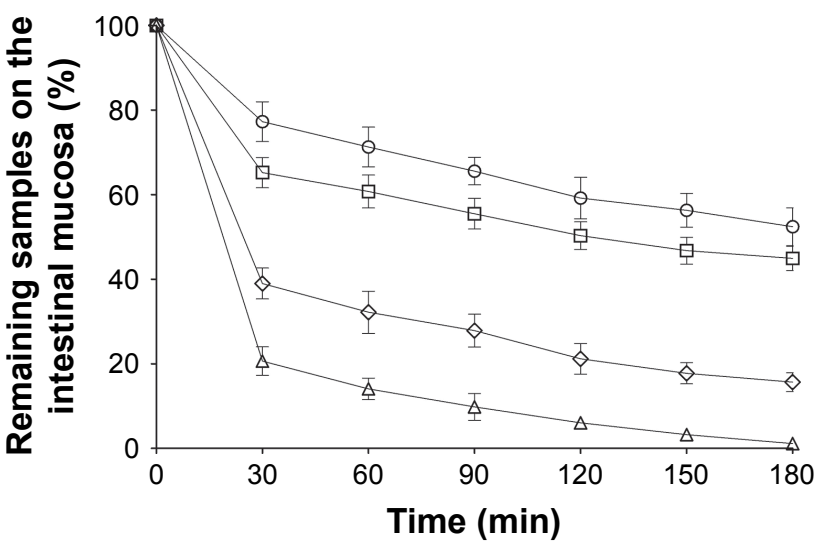

Figure 6 Time course of percentage of remaining thiolated and unmodified betacyclodextrin $(\beta-C D)$ on porcine intestinal mucosa continuously rinsed with $100 \mathrm{mM}$ phosphate buffer $\mathrm{pH} 6.8$ at $37^{\circ} \mathrm{C}$ and $100 \%$ relative humidity.

Notes: $(\bigcirc) \beta-C D-S H_{1200},(\square) \beta-C D-S H_{600},(\diamond)$ fluorescein diacetate (FDA), and $(\Delta)$ $\beta$-CD. Indicated values are mean \pm SD of three experiments.

$\beta$-CD-SH ${ }_{1200}$ increased drug solubility by 157 - and 257 -fold, respectively, in comparison to a just 2-fold improvement in the case of unmodified $\beta-\mathrm{CD}$ (Figure 7).

Hydrophobic properties of miconazole nitrate were reduced by encapsulation, because the lipophilic groups of the drug were trapped within the lipophilic cavity of the intact ring structure of the novel thiolated CDs. ${ }^{31}$ The improved dissolution of inclusion complexes with these thiolated CDs demonstrates their advantage over the first generation of thiolated CDs providing just a 2-fold improvement in the aqueous solubility of miconazole nitrate. ${ }^{1}$

\section{Dissolution studies}

Complexation mechanisms of drug-like chemical compounds with different $\mathrm{CDs}$ to establish a host-guest complex in solution

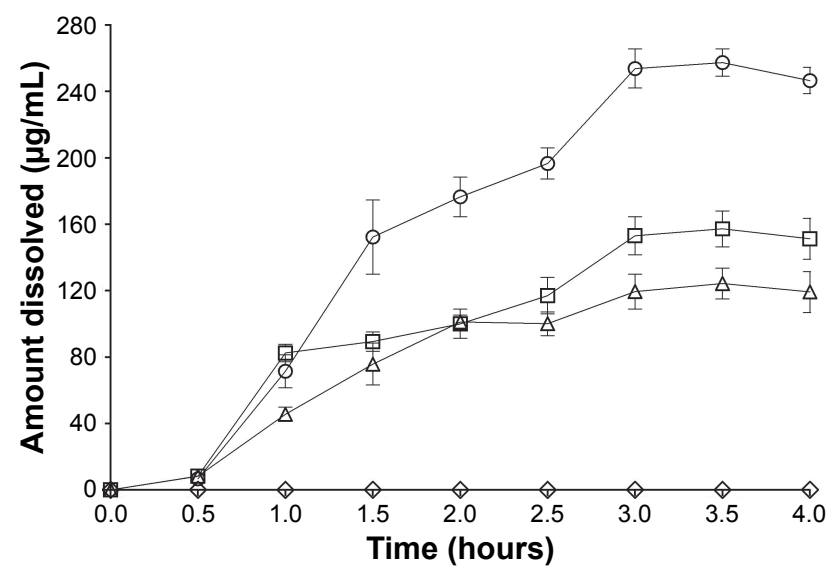

Figure 7 Dissolution profile of miconazole nitrate formulated in the inclusion complex with thiolated and unmodified beta-cyclodextrin $(\beta-C D)$.

Notes: $(\bigcirc) \beta-C D-S H_{600},(\square) \beta-C D-S_{1200},(\Delta) \beta-C D$, and $(\diamond)$ miconazole nitrate (control). All values are the mean $\pm S D$ of triplicate experiments. 
result in the improvement of pharmacokinetic parameters and physicochemical properties of the guest component, such as higher stability, increased aqueous solubility, decreased plasma protein binding, and cellular toxicity. ${ }^{32}$ In order to obtain data about the dissolution kinetic of unmodified and thiolated $\beta-C D /$ miconazole inclusion complexes, dissolution studies were performed. Results showed a significantly different dissolution profile for all tested complexes being based on $\beta-\mathrm{CD}-\mathrm{SH}_{1200}$ exhibiting much higher dissolution velocity than the others. The $\beta$-CD complexes were found to be more stable and soluble in water. Results as illustrated in Figure 7 were in good agreement with solubility data listed in Table S1 showing highest solubility for the $\beta-\mathrm{CD}-\mathrm{SH}_{1200}$ complex followed by the $\beta-\mathrm{CD}-\mathrm{SH}_{600}$ and the unmodified complex.

\section{Moisture content}

Moisture content influences the weight, appearance, and physical properties of the final product. An accurate moisture content determination plays therefore a key role in ensuring quality of CDs. Moisture uptake of the complexes was very low and ranged from about $0.81 \% \pm 0.28 \%$ to $1.19 \% \pm 0.54 \%$ for all three complexes. According to these results, moisture does not seem to have a significant impact on the properties of formed complexes.

\section{Liquid chromatography - mass spectrometry}

Liquid chromatography - mass spectrometry under optimized conditions with ESI mode provided a highly selective method for determination of miconazole. Direct infusion through a syringe pump was used to achieve the most suitable mass spectrometry conditions for miconazole. Methanol acidified with $0.1 \%$ formic acid was identified as the most appropriate eluent. The total run time for miconazole was $3.8 \mathrm{~min}$. The protonated active pharmaceutical ingredient was detected as the major peak in all complexes. The spectrum of complexes showed base peak ions at mass-to-charge ratio $(\mathrm{m} / \mathrm{z})$ of 416.1 for miconazole. The calibration curve was linear for concentrations in the range of 7.81-500 ng/mL and the representative regression equation showed $r^{2}=0.9961$.

The miconazole content was $18.25 \%, 25.71 \%$, and $33.41 \%$ in $\beta$-CD-miconazole, $\beta$-CD-SH600-miconazole, and $\beta$-CD-SH1200-miconazole complexes, respectively, as shown in Table $\mathrm{S} 3$.

\section{Conclusion}

Thiomers are one of the most studied mucoadhesive excipients in drug delivery. In this study, a novel nonionic $\beta-\mathrm{CD}-\mathrm{SH}$ with intact ring structure was developed.
This new generation of $\beta$-CD-SH was compared with a cationic $\beta$-CD-SH of ring-opened structure. The new generation had no toxic effect on the cell even at high concentration (1\%), while the thiolated CD first generation showed a timeand concentration-dependent toxicity. The novel $\beta$-CD-SH showed comparatively high mucoadhesive properties. In contrast to ionic CDs, the new derivative formed stable inclusion complexes with miconazole nitrate and provided improved drug solubility. These favorable properties guarantee the benefits of localized delivery of poorly soluble drugs on mucosal membranes, in particular where gels and creams are irritating, such as the intraoral or ocular mucosa.

\section{Acknowledgment}

The authors would like to thank Shiraz University and University of Innsbruck for supporting this research.

\section{Disclosure}

The authors report no conflicts of interest in this work.

\section{References}

1. Ijaz M, Matuszczak B, Rahmat D, et al. Synthesis and characterization of thiolated $\beta$-cyclodextrin as a novel mucoadhesive excipient for intra-oral drug delivery. Carbohydr Polym. 2015;132:187-195.

2. Ijaz M, Ahmad M, Akhtar N, Laffleur F, Bernkop-Schnürch A. Thiolated $\alpha$-cyclodextrin: the invisible choice to prolong ocular drug residence time. J Pharm Sci. 2016;105(9):2848-2854.

3. Gum JR Jr, Hicks JW, Toribara NW, Rothe EM, Lagace RE, Kim YS. The human MUC2 intestinal mucin has cysteine-rich subdomains located both upstream and downstream of its central repetitive region. J Biol Chem. 1992;267(30):21375-21383.

4. Bernkop-Schnürch A. Thiomers: a new generation of mucoadhesive polymers. Adv Drug Deliv Rev. 2005;57(11):1569-1582.

5. Sarti F, Staaf A, Sakloetsakun D, Bernkop-Schnürch A. Thiolated hydroxyethylcellulose: synthesis and in vitro evaluation. Eur J Pharm Biopharm. 2010;76(3):421-427.

6. Peppas NA, Buri PA. Surface, interfacial and molecular aspects of polymer bioadhesion on soft tissues. J Control Release. 1985;2:257-275.

7. Lehr CM. From sticky stuff to sweet receptors - achievements, limits and novel approaches to bioadhesion. Eur J Drug Metab Pharmacokinet. 1996;21(2):139-148.

8. Shityakov S, Puskás I, Pápai K, et al. Sevoflurane-sulfobutylether$\beta$-cyclodextrin complex: preparation, characterization, cellular toxicity, molecular modeling and blood-brain barrier transport studies. Molecules. 2015;20(6):10264-10279.

9. Kafedjiiski K, Krauland AH, Hoffer MH, Bernkop-Schnürch A. Synthesis and in vitro evaluation of a novel thiolated chitosan. Biomaterials. 2005;26(7):819-826.

10. Schmitz T, Grabovac V, Palmberger TF, Hoffer MH, BernkopSchnürch A. Synthesis and characterization of a chitosan-N-acetyl cysteine conjugate. Int J Pharm. 2008;347(1-2):79-85.

11. Shityakov S, Sohajda T, Puskás I, Roewer N, Förster C, Broscheit JA. Ionization states, cellular toxicity and molecular modeling studies of midazolam complexed with trimethyl- $\beta$-cyclodextrin. Molecules. 2014;19(10):16861-16876.

12. Furuhata K, Koganei K, Chang HS, Aoki N, Sakamoto M. Dissolution of cellulose in lithium bromide-organic solvent systems and homogeneous bromination of cellulose with N-bromosuccinimide-triphenylphosphine in lithium bromide-N,N-dimethylacetamide. Carbohydr Res. 1992; 230(1):165-177. 
13. Iqbal J, Sarti F, Perera G, Bernkop-Schnürch A. Development and in vivo evaluation of an oral drug delivery system for paclitaxel. Biomaterials. 2011;32(1):170-175.

14. Higuchi T, Connors KA. Phase-solubility techniques. Adv Anal Chem Instrum. 1965;4:117-212.

15. Wang JH, Cai Z. Investigation of inclusion complex of miconazole nitrate with $\beta$-cyclodextrin. Carbohydr Polym. 2008;72(2):255-260.

16. Hombach J, Palmberger TF, Bernkop-Schnürch A. Development and in vitro evaluation of a mucoadhesive vaginal delivery system for nystatin. J Pharm Sci. 2009;98(2):555-564.

17. Le HT, Jeon HM, Lim CW, Kim TW. 6-Triazolyl-6-deoxy- $\beta$ cyclodextrin derivatives: synthesis, cellular toxicity, and phasesolubility study. Carbohydr Res. 2014;391:22-28.

18. Ofokansi KC, Kenechukwu FC, Ogwu NN. Design of novel miconazole nitrate transdermal films based on Eudragit RS100 and HPMC hybrids: preparation, physical characterization, in vitro and ex vivo studies. Drug Deliv. 2015;22(8):1078-1085.

19. Fox SC, Li B, Xu D, Edgar KJ. Regioselective esterification and etherification of cellulose: a review. Biomacromolecules. 2011;12(6): 1956-1972.

20. Suchaoin W, Bonengel S, Hussain S, Huck CW, Ma BN, BernkopSchnürch A. Synthesis and in vitro evaluation of thiolated carrageenan. J Pharm Sci. 2015;104(8):2523-2530.

21. Matsui Y, Ishikawa J, Kamitakahara H, Takano T, Nakatsubo F. Facile synthesis of 6-amino-6-deoxycellulose. Carbohydr Res. 2005; 340(7):1403-1406.

22. Coleman AW, Nicolis I, Keller N, Dalbiez JP. Aggregation of cyclodextrins: An explanation of the abnormal solubility of $\beta$-cyclodextrin. J Incl Phenom. 1992;13(2):139-143.

23. Szente L, Szejtli J. Highly soluble cyclodextrin derivatives: chemistry, properties, and trends in development. Adv Drug Deliv Rev. 1999;36(1):17-28
24. Irie T, Uekama K. Pharmaceutical applications of cyclodextrins. III. Toxicological issues and safety evaluation. J Pharm Sci. 1997;86(2): $147-162$.

25. Mukherjee TK, Mishra AK, Mukhopadhyay S, Hoidal JR. High concentration of antioxidants $\mathrm{N}$-acetylcysteine and mitoquinone-Q induces intercellular adhesion molecule 1 and oxidative stress by increasing intracellular glutathione. J Immunol. 2007;178(3):1835-1844.

26. Kanikarla-Marie P, Jain SK. L-Cysteine supplementation reduces high-glucose and ketone-induced adhesion of monocytes to endothelial cells by inhibiting ROS. Mol Cell Biochem. 2014;391(1-2):251-256.

27. Albers E, Müller BW. Cyclodextrin derivatives in pharmaceutics. Crit Rev Ther Drug Carrier Syst. 1995;12(4):311-337.

28. Iqbal J, Shahnaz G, Dünnhaupt S, Müller C, Hintzen F, BernkopSchnürch A. Preactivated thiomers as mucoadhesive polymers for drug delivery. Biomaterials. 2012;33(5):1528-1535.

29. Francois M, Snoeckx E, Putteman P, et al. A mucoadhesive, cyclodextrin-based vaginal cream formulation of itraconazole. AAPS PharmSci. 2003;5(1):E5.

30. Gavini E, Rassu G, Haukvik T, Lanni C, Racchi M, Giunchedi P. Mucoadhesive microspheres for nasal administration of cyclodextrins. J Drug Target. 2009;17(2):168-179.

31. Gidwani B, Vyas A. Synthesis, characterization and application of epichlorohydrin- $\beta$-cyclodextrin polymer. Colloids Surf B Biointerfaces. 2014;114:130-137.

32. Felton LA, Popescu C, Wiley C, Esposito EX, Lefevre P, Hopfinger AJ. Experimental and computational studies of physicochemical properties influence NSAID-cyclodextrin complexation. AAPS PharmSciTech. 2014;15(4):872-881.

33. Kiss T, Fenyvesi F, Bácskay I, et al. Evaluation of the cytotoxicity of $\beta$-cyclodextrin derivatives: Evidence for the role of cholesterol extraction. Eur J Pharm Sci. 2010;40(4):376-380.
International Journal of Nanomedicine

\section{Publish your work in this journal}

The International Journal of Nanomedicine is an international, peerreviewed journal focusing on the application of nanotechnology in diagnostics, therapeutics, and drug delivery systems throughout the biomedical field. This journal is indexed on PubMed Central, MedLine, CAS, SciSearch $\AA$, Current Contents $₫ /$ Clinical Medicine,

\section{Dovepress}

Journal Citation Reports/Science Edition, EMBase, Scopus and the Elsevier Bibliographic databases. The manuscript management system is completely online and includes a very quick and fair peer-review system, which is all easy to use. Visit http://www.dovepress.com/ testimonials.php to read real quotes from published authors. 